\title{
Outcomes in the treatment of carotid body tumor, 20 years of experience
}

\author{
Héctor Gurrola-Machuca ${ }^{1 *}$, Arturo P. Miranda-Aguirre ${ }^{1}$ and Héctor Gurrola-Luna ${ }^{2,3 *}$ \\ ${ }^{1}$ Department of Surgical Oncology, Head and Neck Tumors Section, Centro Médico Nacional 20 de Noviembre; ${ }^{2}$ Social Service Program, Universidad \\ Nacional Autónoma de México; ${ }^{3}$ Department of Nuclear Cardiology, Instituto Nacional de Cardiología "Ignacio Chávez". Mexico City, Mexico
}

\begin{abstract}
Objective: To present the results of the treatment of a series of cases of Carotid Body Tumors (CBT). Material and methods: Retrospective study in which the cases of CBT of patients treated for 20 years were analyzed. The frequency of presentation was analyzed according to the Shamblin classification, the type of treatment used, complications, as well as the results obtained. Results: 55 patients with 62 CBT were included. According to the Shamblin category, we found 4 cases (6.5\%) type I, 44 cases $(71 \%)$ type II and 14 cases (22.6\%) type III. Surgery was performed in $64.5 \%$ of tumors. The median intraoperative bleeding was $350 \mathrm{ml}$, while operative time was $120 \mathrm{~min}$. There were 3 postoperative complications (7.5\%), which included one Horner syndrome, one superior laryngeal nerve lesion and one stroke. In the rest of the patients, treatment was with External Beam Radiation Therapy (EBRT) or surveillance. Conclusions: Surgery is the best treatment option for CBT, especially in Shamblin I and II. Preoperative embolization was not essential for resection of these tumors. EBRT appears to be the best treatment for Shamblin III tumors.
\end{abstract}

Key words: Carotid body tumors. Paragangliomas. Chemodectomas. Therapeutic embolization.

\section{Resultados en el tratamiento del tumor de cuerpo carotídeo, experiencia de 20 años}

\section{Resumen}

Objetivo: Presentar los resultados en el tratamiento de una serie de casos de tumores del cuerpo carotídeo (TCC). Material y métodos: Estudio retrospectivo en el que se analizaron los casos de TCC de pacientes tratados durante 20 años. Se analizó la frecuencia de presentación de acuerdo con la clasificación de Shamblin, el tipo de tratamiento utilizado, las complicaciones y los resultados obtenidos. Resultados: Se incluyeron 55 pacientes con 62 TCC. De acuerdo con la categoría de Shamblin, encontramos 4 casos (6.5\%) tipo I, 44 casos (71\%) tipo II y 14 casos (22.6\%) tipo III. Se realizó cirugía en el $64.5 \%$ de los tumores. La mediana en el sangrado transoperatorio fue de $350 \mathrm{ml}$, el tiempo operatorio fue $120 \mathrm{~min}$. Se presentaron 3 complicaciones posoperatorias (7.5\%), que incluyeron un síndrome de Horner, una lesión del nervio laríngeo superior y un evento vascular cerebral. En el resto de las pacientes el tratamiento fue con radioterapia o vigilancia. Conclusiones: La cirugía es la mejor opción de tratamiento de los TCC, especialmente en los Shamblin I y II. La embolización preoperatoria no fue necesaria para la resección de estos tumores. La radioterapia parece ser el mejor tratamiento en tumores Shamblin III.

Palabras clave: Tumor del cuerpo carotídeo. Paraganglioma. Quimiodectoma. Embolización terapéutica.

\section{Correspondence:}

*Héctor Gurrola-Machuca

E-mail: gurrolamah@ @rodigy.net.mx
Date of reception: 18-01-2021

Date of acceptance: 20-03-2021

DOI: 10.24875/j.gamo.M21000214
Available online: $26-08-2021$ Gac Mex Oncol. 2021;20(3):34-39 www.gamo-smeo.com 1665-9201/@ 2021 Sociedad Mexicana de Oncología. Published by Permanyer. This is an open access article under the terms of the CC BY-NC-ND license (http://creativecommons.org/licenses/by-nc-nd/4.0/). 


\section{Introduction}

Carotid body tumors (CBT) are rare neoplasms, most of which are benign ${ }^{1}$. CBTs are considered slow-growing neuroendocrine neoplasms that arise from the paraganglia cells, which are located at the bifurcation of the common carotid artery. These neoplasms account for $0.6 \%$ of all head and neck tumors, and up to $10 \%$ have a bilateral presentation ${ }^{1,2}$. The first described classification is that proposed by Shamblin in 1971, which to date remains the most widely used ${ }^{3}$. It is a surgical-pathological classification that considers carotid vessels adventitia level of involvement. For the diagnosis of this pathology, physical examination is a fundamental part, and imaging studies, such as ultrasound and tomography, serve to confirm clinical suspicion. The most widely recommended treatment is surgical resection. Most common postoperative complications are cranial nerve lesion, with hypoglossal nerve $(9.6 \%)$, vagus nerve $(8.1 \%)$ and the facial nerve $(2.8 \%)$ being the most affected; Horner syndrome is observed in $2.9 \%$. Other important complications include ischemic stroke (3.5\%), hematoma $(5.2 \%)$ and death $(2.2 \%)^{4}$. The probability of resection and the rate of complications have been described to be associated with Shamblin classification; i.e. for type I and II tumors, it is more probable for resection to be achieved with few complications, in comparison type III tumors, for which the need for vascular grafts placement is even sometimes necessary. The usefulness of radiotherapy as primary, combined or rescue treatment in CBT has also been evaluated ${ }^{5}$. In turn, surveillance represents another option for some cases $^{6}$.

To date, there is an ongoing debate about the usefulness of embolization prior to surgical resection aiming to reduce intraoperative bleeding and even subsequent complications ${ }^{7}$. The purpose of this study was to describe the results in the treatment of a series of CBT cases.

\section{Material and methods}

The medical records of patients who were referred to the head and neck tumors department in a tertiary care hospital with a diagnosis of CBT were reviewed. The patients had to meet the following criteria: being older than 18 years, having been treated during the period comprised between 1991 and 2019, having been followed-up for at least six months, having a complete medical record and imaging studies that confirmed the presence of CBT. The following clinical data were analyzed: age, gender, tumor size, which was evaluated with preoperative tomography, the type of treatment given, category according to the Shamblin classification, surgical time in minutes, intraoperative bleeding and treatment complications. The surgical technique used for CBT excision was similar to that previously described in the literature ${ }^{8}$ and was used for all patients, which, briefly, consists of cervical incision, sub-platysmal flaps dissection, sternocleidomastoid dissection and retraction, common carotid localization and reference; subsequently, internal and external carotid dissection and reference, dissection of the adventitia, starting with internal carotid and continuing with that of external carotid; hypoglossal and pneumogastric nerves are identified and respected, the main nutritional vessel located at the bifurcation is identified, clamped and ligated, and hemostasis, closed drainage placement and closure by planes are carried out. In all patients who underwent surgery, final pathology report confirmed the diagnosis. The results of this cross-sectional, retrospective, retrolective study are described.

\section{Results}

Fifty-five patients with 62 CBTs were included for analysis, out of which 7 cases had bilateral tumors (12.7\%). Women represented almost the entire series, with 53 cases $(96.4 \%)$. All bilateral tumors corresponded to the female gender. Mean age was $54 \pm 14$.3 years. Median tumor size was $4 \mathrm{~cm}$. According to the Shamblin classification, 4 cases corresponded to type I (6.5\%), 44 cases to type II (71\%) and 14 cases to type III (22.6\%). As for treatment, surgery was performed in 40 tumors $(64.5 \%)$, eight patients rejected surgery, and the CBT was considered unresectable in six due to intraoperative findings. Eight patients did not undergo surgery because of the high surgical risk associated with comorbidities, one of them with Shamblin category II and 7 with category III. Median intraoperative bleeding was $350 \mathrm{~mL}$, and for operative time it was $120 \mathrm{~min}$ (Table 1). Surgery was the treatment for all Shamblin type I cases, for 35 Shamblin II cases (77.1\%) and one Shamblin III patient. There were only three postoperative complications $(7.5 \%)$, Horner syndrome in one patient, superior laryngeal nerve injury in another, and one stroke in another, which occurred at fourth day after surgery. In the Shamblin III patient who underwent surgery, placement of a synthetic vascular graft was necessary. As it was to be expected, a directly proportional association was observed between the Shamblin category and intraoperative time and bleeding (Figs. 1 and 2). 


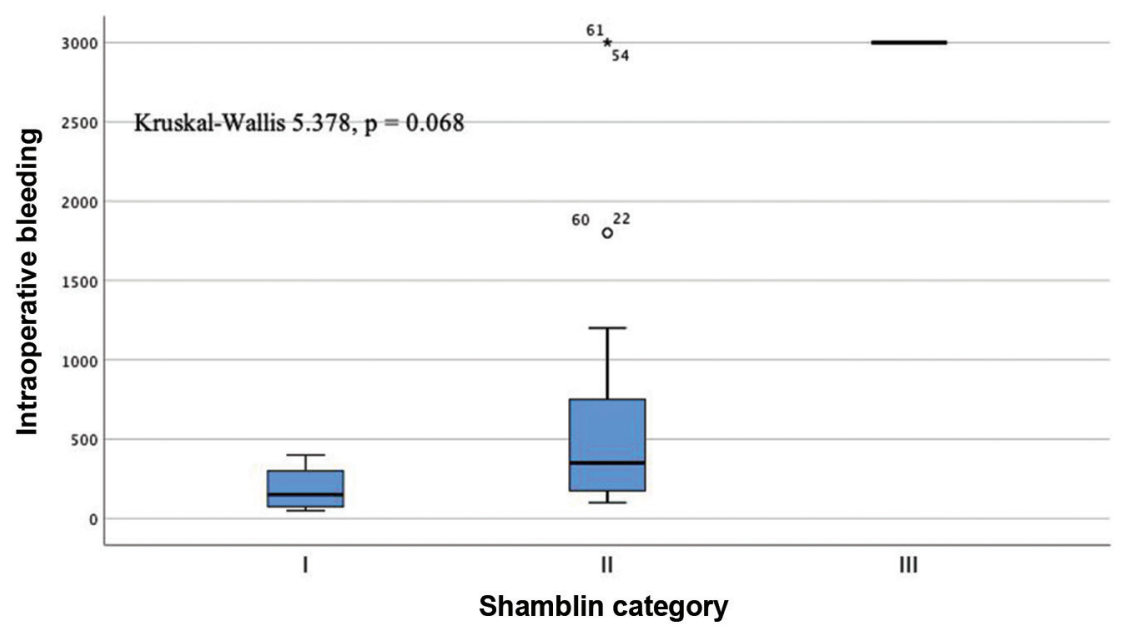

Figure 1. Comparison of operative bleeding according to Shamblin category.

Radiotherapy was the treatment for 10 patients (16.1\%), three because they rejected surgery in a Shamblin II category, four because the lesions were considered unresectable during surgery, and other three who corresponded to patients with high surgical risk, all of them Shamblin III. Twelve patients (19.4\%) underwent surveillance only, six with Shamblin category II and six with Shamblin III (Table 2, Fig. 3). Of the seven patients with bilateral tumors, four underwent bilateral surgery $(7.3 \%)$, one patient underwent surgery on one side and contralateral radiation therapy $(1.8 \%)$, another patient underwent radiotherapy and contralateral surveillance $(1.8 \%)$, and another one received bilateral radiotherapy (1.8\%). Median follow-up in this series was 80 months (2226 months) and patient outcomes were: 40 alive with no evidence of tumor activity (64.5\%), 21 alive with evidence of tumor activity (33.9\%) and one deceased with no evidence of tumor activity (1.6\%).

\section{Discussion}

In this case series, the results of the treatment of 62 CBTs were presented, out of which the majority were treated with surgery with similar results to those recently reported in other studies ${ }^{9,10}$. Several of them, including five systematic reviews, have evaluated the usefulness of preoperative embolization; however, their results have been contradictory regarding the true benefit of this procedure ${ }^{7,11-15}$. In the systematic review by Texakadalis et al., in which 1,326 patients were analyzed, those who underwent preoperative embolization had significantly less bleeding (weighted mean differences
Table 1. Clinical-demographic data of the series of 55 patients with carotid body tumors (CBT)

\begin{tabular}{|l|c|}
\hline CBT & $n=62$ \\
\hline Age, years - Mean (SD) & $54( \pm 14.3)$ \\
\hline Gender, females - n (\%) & $53(96.4 \%)$ \\
\hline Tumor size, cm - Md (range) & $4(2.5-8)$ \\
\hline Shamblin category - n (\%) \\
I \\
II \\
III \\
\hline Type of treatment - n (\%) \\
Surgery \\
Radiotherapy & $44(6.5)$ \\
Surveillance & $14(22.6)$ \\
Operative bleeding, mL - Md (range) & $40(64.5)$ \\
Surgical time, min - Md (range) & $10(16.1)$ \\
\hline Current status n (\%) & $12(19.4)$ \\
ANTA & $120(40-3.000)$ \\
AWTA & \\
DNTA & $40(64.5)$ \\
\hline
\end{tabular}

SD: standard deviation; Md: median; ANTA: alive with no evidence of tumor activity; AWTA: alive with evidence of tumor activity; DNTA: dead with no evidence of tumor activity.

[WMD]: -135.32; 95\% confidence interval [Cl]: -224.58 to -46.06 ) and shorter surgical time (WMD: $-38.71 ; 95 \%$ Cl: -65.61 to -11.62). No significant difference was found in the risk of cranial nerve lesion, ischemic stroke and transient ischemic attack ${ }^{16}$. In another meta-analysis that included fewer patients, a decrease in bleeding was also demonstrated (WMD: $-0.52 ; 95 \% \mathrm{Cl}:-0.77$ to -0.28 ), as well as shorter operative time (WMD: -0.46 ; $95 \%$ 


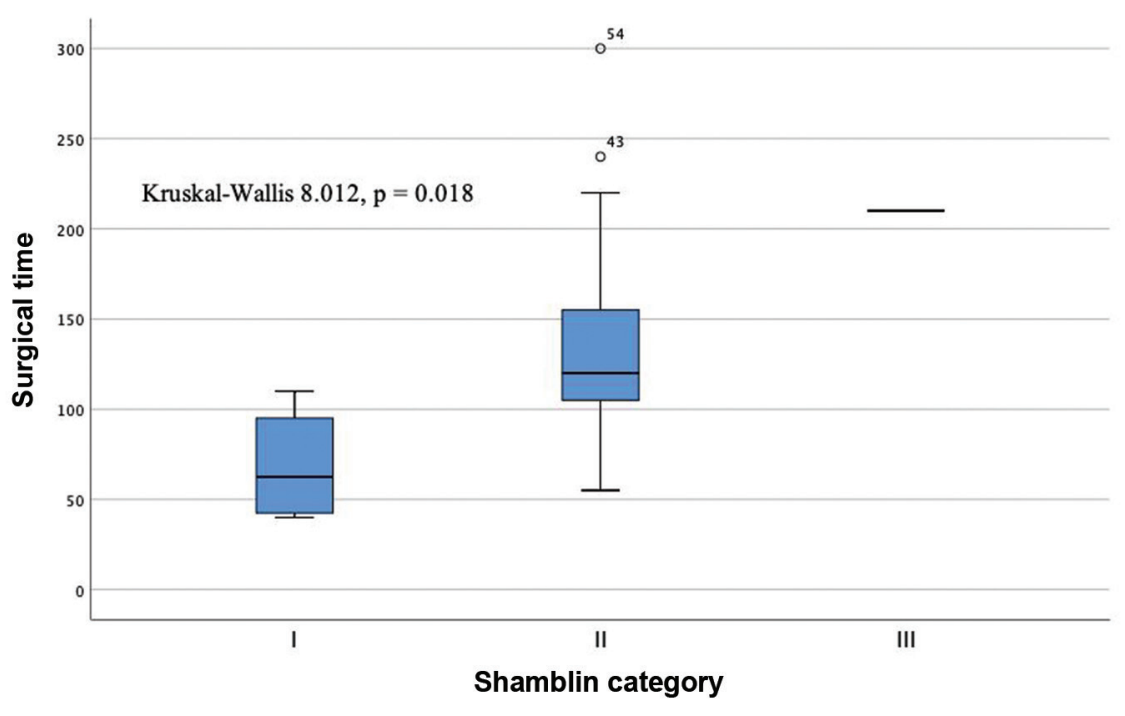

Figure 2. Comparison of surgical time according to Shamblin category.

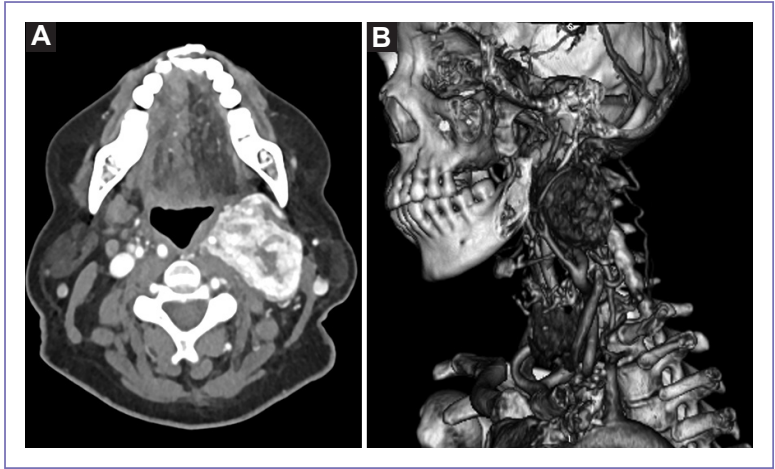

Figure 3. Computed tomography angiography of a patient with a carotid body tumor, categorized as Shamblin III, treated with radiotherapy. A: Axial section. B: 3D reconstruction.

Cl: -0.77 to -0.14 ), with the use of embolization. It is important noting that, in the latter study, the standardized bleeding mean in patients undergoing embolization was $380 \mathrm{~mL}(55-1,123)$, and for operative time it was $200 \mathrm{~min}$ (150-360), which was quite similar to our results ${ }^{17}$. Conversely, in a previous meta-analysis of 470 patients, in which heterogeneity of the studies was also considered for the WMD analysis of the same variables, no significant difference was found in intraoperative bleeding (WMD: $-176.7 ; 95 \% \mathrm{Cl}:-360.61$ to 849 ), or surgical time (WMD: $-0.85 ; 95 \% \mathrm{Cl}:-253$ to 0.83 ), which is why it was concluded that no advantage exists with embolization ${ }^{18}$.
Table 2. Type of treatment provided according to Shamblin category

\begin{tabular}{|l|c|c|c|c|}
\hline \multirow{2}{*}{ Category } & \multicolumn{4}{|c|}{ Type of treatment, $n(\%)$} \\
\cline { 2 - 5 } & Surgery & Radiotherapy & Surveillance & Total \\
\hline I & $4(100)$ & $0(0)$ & $0(0)$ & $4(100)$ \\
\hline II & $35(79.5)$ & $3(6.8)$ & $6(13.6)$ & $44(100)$ \\
\hline III & $1(7.1)$ & $7(50)$ & $6(42.9)$ & $14(100)$ \\
\hline
\end{tabular}

What is evident is that there is a significant association between surgical complications and the Shamblin category. In the aforementioned meta-analysis conducted by Robertson et al., where treatment results of 4,743 CBTs were analyzed, $97 \%$ of these were treated with surgery, with the rate of complications such as stroke being found to be significantly higher in Shamblin III CBTs (4\%), in comparison with Shamblin I and II tiumors ( 1.89 and $2.71 \%$, respectively), as well as for cranial nerve injury $(17 \%$ for Shamblin III vs. 3.76 and $14.4 \%$ for Shamblin I and II, respectively $)^{4}$. However, other studies have not found an association between the Shamblin classification and the rate of complications, but in technical difficulties during resection ${ }^{19}$. Overall complications rate in our study, including the most serious (which was stroke in one patient), accounted for $5.5 \%$, which was very similar to observations described in the literature ${ }^{20,21}$. Some other 
strategies to more accurately determine the risk of intraoperative complications have been described. In a study where new predictors of intraoperative complications were sought, mean distance from the tumor to the base of the skull measured in centimeters was found to be inversely correlated with estimated blood loss, and to be significantly associated with cranial nerve lesion. In turn, tumor volume calculated in $\mathrm{cm}^{3}$ showed a directly proportional correlation with estimated blood loss $^{22}$.

Other complementary surgical techniques intended to reduce the risk of complications and intraoperative bleeding have also been described, including: craniocaudal dissection, use of ultrasonic dissector and advanced bipolar energy, as well as preoperative stents placement and intraoperative shunts. All of them with a limited number of cases, but with apparently good results ${ }^{23-28}$.

Regarding the usefulness of radiotherapy in the treatment of CBT, in a systematic review that compared the results of surgery vs. 127 patients treated with this strategy, the rate of disease control, defined as tumor regression or absence of growth, was found to be of up to $94.5 \%$; tumor reduction was documented in $25 \%$, while absence of growth accounted for $69.3 \%$. Only $5.5 \%$ of the patients had CBT growth. Radiotherapy treatment complications were practically absent: only one patient had central nervous system syndrome. When the results of radiotherapy were compared with those of surgery, although no difference was found in disease control and deaths, there was a difference in major complications and cranial nerve lesions $(p=0.047$ and 0.001 , respectively). For this reason, the study concludes that patients with bulky CBTs that entirely encase the carotid artery or affect the cranial floor should be treated with radiotherapy ${ }^{29}$. Robotic radiosurgery with CyberKnife $^{\circledR}$ has also been described for the treatment of these tumors, with similar results ${ }^{30}$.

According to the above, and considering the marginal or non-existent benefit of preoperative embolization, surgery-associated morbidity, and the good results with radiotherapy, we recommend that patients with Shamblin III tumors should preferably be treated with radiotherapy ${ }^{31}$.

On the other hand, CBT surveillance has also been described in some highly selected patients; for example, those with an advanced age at diagnosis, bulky tumors and who are asymptomatic, given that the probability of stability is up to $42 \%$, and another large percentage will have very slow tumor growth. Close surveillance is important in these cases in order to determine if any of these tumors will require treatment in the future ${ }^{32}$.

Those patients who did not undergo surgery, either because their neoplasm were considered unresectable, or because they did not accept the procedure, were previously discussed by the multidisciplinary team to discern between treatment with radiotherapy or keeping them under surveillance. After deciding the type of behavior, each patient received close surveillance with imaging studies at least every six months. At the time of closure of this study, there were no cases with CBT growth with this behavior.

In our study, the frequency of bilateral tumors was higher than the 7\% reported in other series; although most of them underwent surgery, radiotherapy and surveillance were also strategies in the management of these patients, with low complication rates being achieved, similar to the previously reported rate of $37.5 \%{ }^{33}$.

In this case series, no metastatic CBT was recorded. We have avoided the use of the term "malignant CBT", since in the 2007 update of the World Health Organization classification it was abandoned, given that there is no accepted histological system for the evaluation of the aggressive biological behavior of these tumors ${ }^{34}$. Therefore, instead, the term "malignant" has been replaced by "metastatic" to refer tumors of aggressive behavior, which have been reported in up to $10 \%$ of cases $^{35}$.

Finally, although the results of the treatment strategies used in our series appear to be similar to those reported in the literature, we recognize that their main limitations are: that it was a retrospectively analyzed case series and that very few cases of Shamblin I CBT were recorded; the latter is probably the result of diagnostic delay or later referral.

\section{Conclusions}

CBTs are rare neoplasms, mostly benign and of slow growth. The Shamblin classification remains useful for predicting resectability and postoperative complications. Shamblin I and II CBTs are the most common presentations of these tumors, and in these cases surgery is the most appropriate treatment, with acceptable morbidity. According to our results, no preoperative embolization is required for $\mathrm{CBT}$ resection to be carried out. Conversely, in Shamblin III tumors, radiotherapy appears to be the most appropriate treatment, due to its good results and to the fact that surgery is associated with a high rate of complications. Finally, active 
surveillance is another alternative for those patients who do not accept the risk of surgery or in whom administering radiotherapy is not possible.

\section{Acknowledgements}

To the patients, who trusted us.

\section{Funding}

The authors declare that no funding was received for the development and writing of this manuscript.

\section{Conflict of interests}

The authors declare that there were no conflicts of interest during the development and writing of this manuscript.

\section{Ethical disclosures}

Protection of human and animal subjects. The authors declare that no experiments were performed on humans or animals for this research.

Confidentiality of data. The authors declare that they have followed the protocols of their work center on the publication of patient data.

Right to privacy and informed consent. The authors have obtained informed consent from the patients and/or subjects referred to in the article. This document is in the possession of the corresponding author.

\section{References}

1. Naik SM, Shenoy AM, Nanjundappa, et al. Paragangliomas of the carotid body: Current management protocols and review of literature. Indian $\mathrm{J}$ Surg Oncol. 2013;4(3):305-12.

2. Kaygusuz I, Karlidag T, Keles E, Yalcin S, Yüksel K. Carotid body tumor: Clinical features. J Craniofac Surg. 2015;26(7):e586-e589.

3. Shamblin WR, ReMine WH, Sheps SG, Harrison EG. Carotid body tumor (chemodectoma). Am J Surg. 1971;122(6):732-9.

4. Robertson V, Poli F, Hobson B, Saratzis A, Ross Naylor A. A systematic review and meta-analysis of the presentation and surgical management of patients with carotid body tumours. Eur J Vasc Endovasc Surg. 2019;57(4):477-86.

5. Hansen HS, Thomsen KA. Radiotherapy in glomus tumours (paragangliomas). A 25 year-review. Acta Otolaryngol Suppl. 1988;105(sup449):151-4

6. Rodríguez-Cuevas S, López-Garza J, Labastida-Almendaro S. Carotid body tumors in inhabitants of altitudes higher than 2000 meters above sea level. Head Neck. 1998;20(5):374-78.

7. Inan HC, Yener HM, Karaman E, Kizilkiliç O, Cansiz H, Eker Ç. Role of preoperative embolization in surgical treatment of the carotid body paragangliomas. J Craniofac Surg. 2019;30(3):e267-e270.

9. Sevil FC, Tort M, Kaygin MA. Carotid body tumor resection: Long-term outcome of 67 cases without preoperative embolization. Ann Vasc Surg. 2020;67:200-7.

10. Mascia D, Esposito G, Ferrante A, Grandi A, Melissano G, Chiesa R. Carotid body tumor contemporary management in a high-volume center. J Cardiovasc Surg (Torino). 2020;61(4):459-66.
11. Kuchakulla M, Shah AH, Armstrong V, Jernigan S, Bhatia S, Niazi TN. Multimodal management of pediatric carotid body tumors: a systematic review and case illustrations. J Neurosurg Pediatr. 2018;23(3):325-32.

12. Han T, Wang S, Wei X, Xie $Y$, Sun $Y$, Sun H, et al. Outcome of surgical treatment for carotid body tumors in different shambling type without preoperative embolization: A single-center retrospective study. Ann Vasc Surg. 2020;63:325-31.

13. Liu J, Li Y, Yang L, Cai H. Surgical resection of carotid body tumors with versus without preoperative embolization: Retrospective case-control study. Head Neck. 2018;40(12):2590-5.

14. Zhang T, Jiang W, Li Y, Li B, Yamakawa T. Perioperative approach in the surgical management of carotid body tumors. Ann Vasc Surg. 2012;26(6):775-82.

15. Power AH, Bower TC, Kasperbauer J, Link MJ, Oderich G, Cloft H, et al. Impact of preoperative embolization on outcomes of carotid body tumor resections. J Vasc Surg. 2012;56(4):979-89.

16. Texakalidis P, Charisis N, Giannopoulos S, Xenos D, Rangel-Castilla L, Tassiopoulos AK, et al. Role of preoperative embolization in carotid body tumor surgery: A systematic review and meta-analysis. World Neurosurg. 2019;129:503-513.e2.

17. Jackson RS, Myhill JA, Padhya TA, McCaffrey JC, McCaffrey TV, Mhaskar RS. The effects of preoperative embolization on carotid body paraganglioma surgery: A systematic review and meta-analysis. Otolaryngol Head Neck Surg. 2015;153(6):943-50.

18. Abu-Ghanem S, Yehuda M, Carmel NN, Abergel A, Fliss DM. Impact of preoperative embolization on the outcomes of carotid body tumor surgery: A meta-analysis and review of the literature: Preoperative embolization of carotid body tumor. Head Neck. 2016;38(S1):E2386-E2394.

19. Law $Y$, Chan $Y$, Cheng S. Surgical management of carotid body tumor - Is Shamblin classification sufficient to predict surgical outcome? Vascular. 2017;25(2):184-9.

20. Dorobisz K, Dorobisz T, Temporale H, Zato囚ski T, Kubacka M, Chabowski M, et al. Diagnostic and therapeutic difficulties in carotid body paragangliomas, based on clinical experience and a review of the literature. Adv Clin Exp Med. 2016;25(6):1173-7.

21. Amato B, Serra R, Fappiano F, Rossi R, Danzi M, Milone M, et al. Surgical complications of carotid body tumors surgery: a review. Int Angiol. 2015;34(6 Suppl 1):15-22.

22. Kim GY, Lawrence PF, Moridzadeh RS, Zimmerman K, Munoz A, Luna-Ortiz K, et al. New predictors of complications in carotid body tumor resection. J Vasc Surg. 2017;65(6):1673-9.

23. Paridaans MPM, van der Bogt KEA, Jansen JC, Nyns EC, Wolterbeek R, van Baalen JM, et al. Results from craniocaudal carotid body tumor resection: Should it be the standard surgical approach? Eur J Vasc Endovasc Surg. 2013;46(6):624-9.

24. Ferreira J, Canedo A, Braga S, Vasconcelos J, Gouveia R, Martins V, et al. Carotid body tumours resection with ultrasound dissector. Chin Med $\mathrm{J}$ (Engl). 2013;126(3):586-8.

25. Luna-Ortiz K, Villavicencio-Valencia V, Carmona-Luna T, Cano-Valdez AM, Herrera Gómez A. Resección de tumor de cuerpo carotídeo con LigaSureß. Acta Otorrinolaringol Esp. 2010;61(1):6-11.

26. Piazza P, Di Lella F, Bacciu A, Di Trapani G, Ait Mimoune H, Sanna M. Preoperative protective stenting of the internal carotid artery in the management of complex head and neck paragangliomas: Long-term results. Audiol Neurotol. 2013;18(6):345-52.

27. Zeng G, Zhao J, Ma Y, Huang B. Resection of carotid body tumors and the additional choice of intraoperative shunt in complicated tumors. Ann Vasc Surg. 2012;26(4):511-5.

28. Scanlon JM, Lustgarten JJ, Karr SB, Cahan JI. Successful devascularization of carotid body tumors by covered stent placement in the external carotid artery. J Vasc Surg. 2008;48(5):1322-4.

29. Suárez C, Rodrigo JP, Mendenhall WM, Hamoir M, Silver CE, Grégoire V, et al. Carotid body paragangliomas: a systematic study on management with surgery and radiotherapy. Eur Arch Otorhinolaryngol. 2014;271(1):23-34.

30. Bianchi LC, Marchetti M, Brait L, Bergantin A, Milanesi I, Broggi G, et al. Paragangliomas of head and neck: a treatment option with CyberKnife radiosurgery. Neurol Sci. 2009;30(6):479-85.

31. Gilbo P, Morris CG, Amdur RJ, Werning JW, Dziegielewski PT, Kirwan J, et al. Radiotherapy for benign head and neck paragangliomas: A 45-year experience: RT for Head and Neck Paragangliomas. Cancer. 2014;120(23):3738-43.

32. Langerman A, Athavale SM, Rangarajan SV, Sinard RJ, Netterville JL. Natural history of cervical paragangliomas: outcomes of observation of 43 patients. Arch Otolaryngol Head Neck Surg. 2012;138(4):341-5.

33. Bobadilla-Rosado LO, Garcia-Alva R, Anaya-Ayala JE, Peralta-Vazquez C, Hernandez-Sotelo K, Luna L, et al. Surgical management of bilateral carotid body tumors. Ann Vasc Surg. 2019;57:187-93.

34. WHO Classification of Tumours of Endocrine Organs. 4th edition. International Agency for Research on Cancer; 2017.

35. Lam AK. Update on adrenal tumours in 2017 World Health Organization (WHO) of endocrine tumours. Endocr Pathol. 2017;28(3):213-27. 